\title{
To Treat or to Teach: Comparing Strategies to Reduce Escape- Maintained Behavior
}

Lucie M. Romano

Follow this and additional works at: https://researchrepository.wvu.edu/etd

\section{Recommended Citation}

Romano, Lucie M., "To Treat or to Teach: Comparing Strategies to Reduce Escape-Maintained Behavior" (2018). Graduate Theses, Dissertations, and Problem Reports. 6528.

https://researchrepository.wvu.edu/etd/6528

This Thesis is protected by copyright and/or related rights. It has been brought to you by the The Research Repository @ WVU with permission from the rights-holder(s). You are free to use this Thesis in any way that is permitted by the copyright and related rights legislation that applies to your use. For other uses you must obtain permission from the rights-holder(s) directly, unless additional rights are indicated by a Creative Commons license in the record and/ or on the work itself. This Thesis has been accepted for inclusion in WVU Graduate Theses, Dissertations, and Problem Reports collection by an authorized administrator of The Research Repository @ WVU. For more information, please contact researchrepository@mail.wvu.edu. 
To Treat or to Teach: Comparing Strategies to Reduce Escape-Maintained Behavior

\author{
Lucie M. Romano
}

Thesis submitted to the Eberly College of Arts and Sciences at West Virginia University in partial fulfillment of the requirements for the degree of

\author{
Masters of Science in \\ Psychology
}

\author{
Claire St. Peter, Ph.D., Chair \\ Kerri Milyko, Ph.D. \\ Hawley Montgomery-Downs, Ph.D.
}

Department of Psychology

\author{
Morgantown, West Virginia \\ 2017
}

Keywords: Differential Reinforcement; Negative Reinforcement; Curricular Revision;

Challenging Behavior

Copyright 2017 Lucie M. Romano 


\section{ABSTRACT \\ To Treat or to Teach: Comparing Strategies to Reduce Escape-Maintained Behavior}

\section{Lucie M. Romano}

Differential negative reinforcement of alternative behavior (DNRA) reduces escape-maintained challenging behavior, but can result in lost instructional time. Instructional time could be maintained through interventions like curricular revision (CR), but the efficacy of CR is less established. We compared DNRA and CR for 3 children with age-typical intellectual functioning whose challenging behavior was maintained by escape from academic tasks. During DNRA, we taught the child to appropriately request a different, mastered task. During CR, we broke the original task into simpler components until the child mastered each component, but still permitted escape following challenging behavior. Curricular revision resulted in less challenging behavior than DNRA for one participant. For the other two participants, DNRA was initially more effective than $\mathrm{CR}$, but participants rarely engaged with the academic task. Challenging behavior was equally suppressed across conditions once extinction for challenging behavior was added to CR. Curricular revision also resulted in each child spending substantially more time engaged with the new task than the mastered task. Curricular revision did not increase the likelihood of treatment relapse relative to DNRA for any participant. Thus, CR may be a desirable option for treating escape-maintained behavior. 


\section{Table of Contents}

To Treat or to Teach: Comparing Strategies to Reduce Escape-Maintained Behavior......... 1

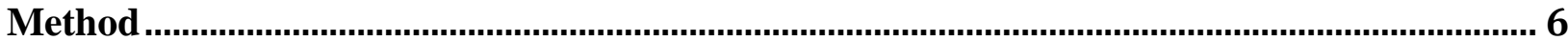

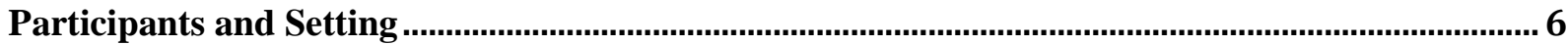

Data Collection, Interobserver Agreement, and Treatment Integrity .................................................. 8

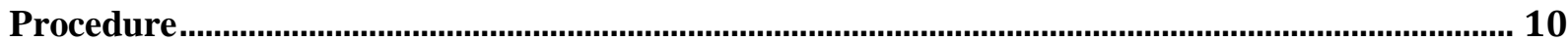

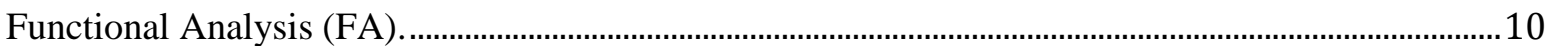

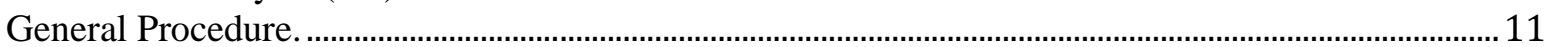

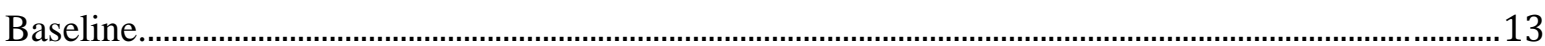

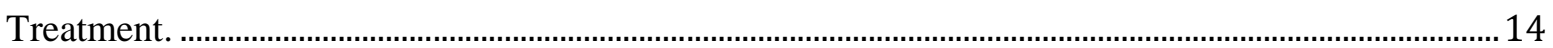

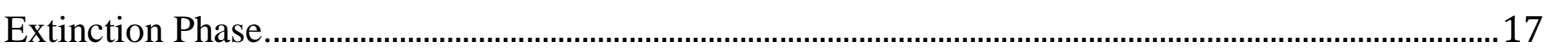

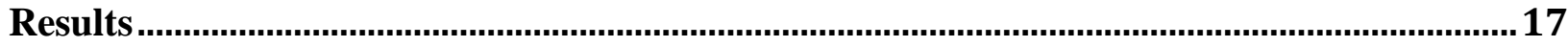

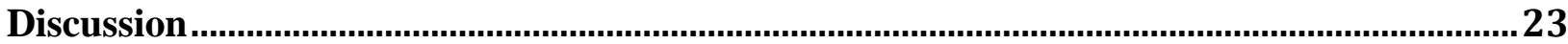

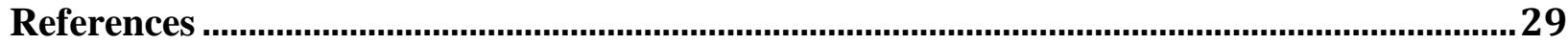

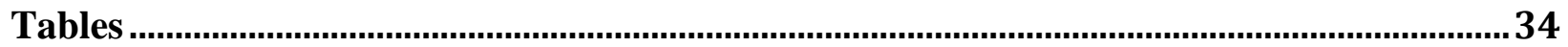

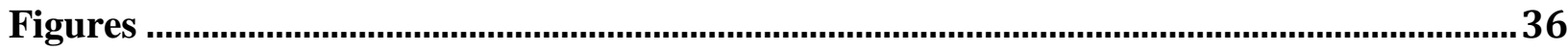

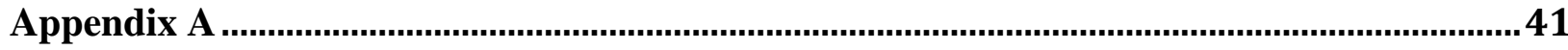

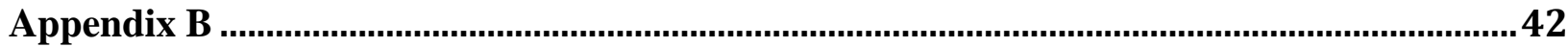


To Treat or to Teach: Comparing Strategies to Reduce Escape-Maintained Behavior Challenging behavior can occur in many different forms (e.g., aggression, noncompliance, self-injurious behavior) and across a variety of populations (e.g., children with Autism Spectrum Disorders, adults with developmental disabilities, typically developing adolescents). Behavior analysts use methods such as functional analyses (FA) to determine what aspects of the environment are maintaining the challenging behavior (e.g., Iwata, Dorsey, Slifer, Bauman, \& Richman, 1982/1994). Certain aspects of the environment, such as novel tasks, the duration of tasks, the difficulty of tasks, and other potentially aversive stimuli, can trigger behavior that results in the termination of the task (e.g., Geiger, Carr, \& LeBlanc, 2010; Smith, Iwata, Goh, \& Shore, 1995). When the task is terminated following challenging behavior, it increases the likelihood that the challenging behavior will occur again in the presence of that aspect of the environment. When children engage in behavior that results in the termination of a task, we say that their behavior is maintained by escape from the aversive aspects of the environment or, more commonly, escape from demands.

Escape from demands is a frequently identified function of challenging behavior. In 2004, Asmus and colleagues examined the function of challenging behavior among 138 participants with and without developmental disabilities. They identified escape (negative reinforcement) as the function of challenging behavior for $29 \%$ of participants. Additionally, $40 \%$ of functions were identified as escape in combination with positive reinforcement (attention or access to tangible items). More recently, Beavers, Iwata, and Lerman (2013) reviewed 435 functional-analysis studies that included children with and without disabilities. Of the 435 reviewed publications, the authors examined 981 individual line graphs and found that 32.2\% of the functional-analysis cases resulted in the identification of an escape function. Because of this 
high prevalence, effective interventions targeting escape-maintained behavior are critical to improve the success of individuals who engage in challenging behavior.

One well-established intervention for escape-maintained challenging behavior is differential negative reinforcement of alternative behavior (DNRA). Differential reinforcement can be implemented to teach the child to appropriately request a break from the task without engaging in challenging behavior. Interventions based on differential reinforcement are frequently used and recommended in therapeutic settings. However, Geiger et al. (2010) recommend curricular revision as an intervention for escape-maintained behavior before attempting DNRA when instruction is not optimal. In other words, when aspects of the instructional environment are aversive as indicated by Geiger et al. and Smith et al. (1995), teachers and caregivers should revise and reintroduce the task as an initial intervention.

Curricular revision involves revising aspects of academic tasks so that they are no longer aversive to the learner. For example, Dunlap, Kern-Dunlap, Clarke, and Robbins (1991) implemented curricular-revision interventions to reduce the challenging behaviors of an adolescent female with multiple diagnoses in a public school special-education program. Multiple contingency-based interventions had been previously implemented without success. Results of a functional behavior assessment (FBA) indicated that her challenging behavior was potentially maintained by escape from aversive aspects of her academic instruction. The authors modified the delivery of instruction by shortening non-preferred-work sessions and arranging the materials so that the number of required responses was visually clear, interspersing gross-motor with fine-motor tasks, arranging the work activities so that the content was interesting and the successful completion of work was followed with concrete, preferred outcomes, and providing choices between tasks to complete. This form of curricular revision immediately and 
dramatically decreased challenging behavior, and the effects were maintained across the remainder of the school year. Using curricular revision as a treatment for escape-maintained behaviors can suppress challenging behavior without the loss of instruction time.

Curricular revision can be implemented in a variety of ways. An academic task is revised specifically to the learner's needs in that the properties of the task that are aversive to the learner are modified to meet the learner’s need. Curricular revision has previously been implemented by shortening the duration of tasks, signaling the end of tasks, allowing the child to choose the order in which she completes the tasks (Dunlap et al., 1991), providing items to facilitate the completion of the task (e.g., a calculator, counting manipulatives), avoiding repetition of work that has already been completed (McComas, Hoch, Paone, \& El-Roy, 2000), varying the types of tasks the child must complete (Dunlap et al., 1991; Winterling, Dunlap, \& O’Neill, 1987), and delivering demands that have a high probability of compliance before delivering the target demand (Singer, Singer, \& Horner, 1987). Each of these interventions has successfully reduced challenging behavior while allowing the child to still engage in necessary academic skills.

Academic skills consist of smaller component skills and larger, broader composite skills (Johnson \& Street, 2013). An example of a component skill is the ability to play scales on a piano, while the composite skill is the ability to improvise a jazz-piano piece (Johnson \& Layng, 1996). One must master the component skills of the piano before mastering the composite skill. Students who do not master the initial component skills will likely struggle to master the composite skills as well (Johnson \& Layng, 1992).

To achieve mastery of a composite skill, it is necessary to be fluent at the component skills. According to Johnson and Layng (1996), fluency refers to behavior that is "flowing, effortless, well-practiced, and accurate” (p. 281). Academic skills should be practiced until they 
are fluent so that they can be accurately utilized when presented with new environmental contingencies (Johnson \& Layng, 1992). To achieve fluency, component skills can be repeatedly practiced in set durations called timings. One way to utilize timings and build fluency is through curricular revision. Although curricular revision can allow the learner to be engaged in academic skills and has suppressed challenging behavior in a few studies (Dunlap \& Kern, 1996), the current literature focuses mainly on DNRA as an intervention for escape-maintained behavior.

Differential negative reinforcement of alternative behavior involves delivering escape from the aversive context contingent upon an appropriate alternative response, such as compliance, while placing challenging behavior on extinction (Vollmer \& Iwata, 1992). For example, Vollmer, Roane, Ringdahl, and Marcus (1999) implemented a DNRA procedure for two children who engaged in escape-maintained challenging behavior. During this intervention, challenging behavior was placed on extinction and a 30-s break from the task was delivered contingent upon compliance with demands. In other words, if the child complied with a verbal prompt or a gestural model to complete an academic task, the experimenter would say, "take a break" and allow 30 s of time away from instruction. If challenging behavior occurred, the experimenter would continue to prompt and eventually physically guide the child to complete the task. This intervention successfully reduced challenging behavior and increased appropriate behavior for both children.

Functional communication training (FCT) can be implemented as a DNRA procedure in which a child who engages in escape-maintained challenging behavior is taught an appropriate communicative response (e.g., “can I have a break, please?”) to gain access to escape in a socially acceptable manner (Carr \& Durand, 1985). For example, Lalli et al. (1995) used functional communication training with three individuals with moderate mental retardation [sic] 
who engaged in high rates of severe challenging behavior that was identified as being maintained by escape from demands through a functional analysis. The participants were taught a verbal response (such as “no”) and were prompted to use the response if they did not want to complete the task. Engaging in the verbal response resulted in descriptive praise and a 30-s break from the task; demands continued following challenging behavior (that is, challenging behavior was placed on extinction). The implementation of FCT in conjunction with escape extinction eliminated challenging behavior and increased independent vocalizations for all participants. Procedures such as FCT not only suppress challenging escape-maintained behavior, but also increase appropriate alternative behavior such as communicative responses.

Differential-reinforcement procedures suppress challenging behavior across a wide range of populations (Lennox, Miltenberger, Spengler, \& Erfanian, 1988; Carr \& Durand, 1985; Wacker et al., 1990; Vollmer \& Iwata, 1992; Lalli, Casey, \& Kates, 1995; Petscher, Rey, \& Bailey, 2009). Best-practice recommendations for DNRA include initially reinforcing every appropriate alternative response then gradually reducing the frequency of reinforcement over time (Greer, Fisher, Saini, Owen, \& Jones, 2016; Hagopian, Boelter, \& Jarmolowicz, 2011; Tiger et al., 2008). The initially dense reinforcement schedule can be difficult for caregivers to implement. Additionally, DNRA procedures often result in extended time away from instruction. For example, the participants in the study by Lalli et al. (1995) never completed the task because escape was always provided for the verbal response. Time away from instruction can result in low rates of skill acquisition and can be detrimental when building foundational academic skills. Another disadvantage of interventions based on differential reinforcement is that abrupt discontinuation of differential-reinforcement procedures can result in treatment relapse (Volkert, Lerman, Call, \& Trossclair-Lasserre, 2009). 
One form of treatment relapse that can occur following the discontinuation of differential reinforcement procedures is resurgence (Doughty, daSilva, \& Lattal, 2007; Lieving \& Lattal, 2003; Marsteller \& St. Peter, 2012; Marsteller \& St. Peter, 2014; Volkert et al., 2009). Resurgence refers to the reemergence of a previously reinforced behavior following the extinction of a more recently reinforced behavior. For example, Volkert and colleagues (2009) used FCT to successfully reduce challenging behavior, but challenging behavior resurged to near-baseline levels when FCT was discontinued. Resurgence often occurs following discontinuation of differential reinforcement procedures like FCT, but it is unknown whether resurgence occurs following curricular revision.

To our knowledge, there has been no direct comparison of the treatment effects of curricular revision and DNRA. Thus, the current study used a multielement design embedded within a multiple-baseline design to compare rates of escape-maintained challenging behavior during curricular revision and DNRA within subject. First, we introduced two similar but distinct tasks that evoked challenging behavior maintained by escape from demands. Then, we implemented differential reinforcement and curricular revision to compare the efficacy of the treatments. As a secondary purpose of the study, we abruptly discontinued treatment to assess the extent to which challenging behavior resurged.

\section{Method}

\section{Participants and Setting}

Three male students ranging in age from 6 to 10 years old participated in the study. Each student engaged in severe challenging behavior and received behavior-analytic services at an elementary alternative-education program. Each participant was expected to attend the alternative-elementary program for a full school day, 5 days a week. The teachers at the program 
were Board Certified Behavior Analysts. Participants spoke in complete sentences that were similar to their same-age peers. Each participant had some prior experience with fluency timings. Participants’ academic skills sometimes lagged behind grade norms. All procedures were approved by the West Virginia University Institutional Review Board. We obtained parental consent for all participants and child assent for those over the age of 7 years. We used pseudonyms for all participants to maintain confidentiality.

We conducted informal interviews with the participants' teachers to determine a target behavior and preferred, mastered academic activities and to identify two skip-count sequences that were not already part of the child's curriculum. We asked teachers to identify academic activities during which each participant frequently engaged in challenging behavior and activities during which each participant engaged in appropriate behavior and seemed to enjoy. We also reviewed participants’ records to identify challenging behaviors that had been previously identified as being maintained by escape via an FBA.

Ian was a 6-year-old male who was diagnosed with Attention Deficit Hyperactivity Disorder (ADHD) and Oppositional Defiant Disorder (ODD). Ian had approximately 1 year of experience with fluency timings and was exposed to at least 2 min total of fluency timings per day in his classroom during the current study. Ian frequently protested (e.g., “no,” "I don’t want to,” “I can’t,” or “stop”), which was identified as an escape-maintained behavior via a previous FA that was conducted at his current school by another behavior consultant. Before each session, Ian chose between a dice math game, a dinosaur activity book, addition and subtraction workbooks, reading books, an iPad with academic games, or addition and subtraction flashcards. The dice math game was eventually replaced with a time-telling game because Ian consistently 
threw the dice out of the session area. Sessions took place at a table in the back of one of Ian's classrooms and lasted for 12 days between September 14, 2016 and October 4, 2016.

Wade was a 6-year-old male who was diagnosed with ADHD. Wade had approximately 1 month of experience with fluency timings and was exposed to at least 2 min total of fluency timings per day in his classroom during the current study. Wade frequently protested (e.g., "no,” “I don’t want to,” “I can’t,” “mm-mm,” or “uh-uh”), which was identified as an escapemaintained behavior via a previous FBA that was conducted at his current school by another behavior consultant. Before each session, Wade chose between a dinosaur activity book, a sorting game, reading books, an iPad with academic games, a grade-level math workbook, or a coloring book. Sessions took place in the hallway outside of Wade's classroom and lasted for 26 days between October, 21, 2016 and December 15, 2016.

Keith was a 10-year-old male who was diagnosed with ADHD, Bipolar Disorder, and a traumatic brain injury. Keith had approximately 5 months of experience with fluency timings and was exposed to at least 5 min total of fluency timings per day in his classroom during the current study. Keith frequently protested (e.g., “no,” “I don’t want to,” “I can’t,” "I hate [x],” “I don’t like $[\mathrm{x}]$,” or “[x] sucks”), which was identified as an escape-maintained behavior through a previous FBA that was conducted at his current school by another behavior consultant. Before each session, Keith chose between a comic book storyboard, coloring pages, a hangman game, a brain teaser book, puzzles, or a writing journal. Sessions took place in the hallway outside of Keith’s classroom and lasted for 20 days between February 24, 2017 and March 29, 2017.

\section{Data Collection, Interobserver Agreement, and Treatment Integrity}

Trained observers collected data using Behavior Logger ${ }^{\mathrm{TM}}$ software on the frequency of correct and incorrect academic responses, target challenging behavior, requests for a break, and 
the percentage of time on break. Correct responses were defined as the child stating the correct number in the skip-count sequence. We considered the number stated to be correct only if it followed the correct prior number. For example, if the child said “4, 8, 12, 16...”, each number would be correct, whereas if the child said “4, $8,9,12,16 \ldots$ ”, the 9 and the 12 would be incorrect because 9 does not follow 8 and 12 does not follow 9 in that sequence. The 16 would be correct, however, because it does follow 12. Additionally, if the child started the sequence over, the first number in the sequence would only be correct if it followed the last number in the sequence. In other words, he could not just say “4, 8, 12, 4, 8, 12...” and be counted correct each time. Incorrect responses were defined as the child stating the wrong number in the skip-count sequence such as in the previous examples. Target challenging behavior was protesting as defined in the participant descriptions (above). A break request was defined as the child saying "please.” A break was defined as the child having access to the chosen academic activity and the experimenter ceasing skip-count prompts.

A second, independent observer also collected data during 33.6\% of sessions for Wade, 43.8\% of sessions for Ian, and $54.4 \%$ of sessions for Keith using BehaviorLogger ${ }^{\mathrm{TM}}$. We also calculated interobserver agreement (IOA) via BehaviorLogger ${ }^{\mathrm{TM}}$. The program divided each observer's data into 10-s intervals and divided the smaller count of each response by the larger count of each response and converted these into percentages. If neither observer recorded a response, that interval was counted as $100 \%$ agreement. The percentage for each interval was then averaged to obtain the IOA for each response. Scores were above $90 \%$ for all responses for each participant. The average IOA score for each response and each participant can be found in Table 1. 
The experimenter collected data via pencil and paper on the number of correct responses to provide the student with immediate feedback about his performance. An independent observer(s) collected data on all dependent measures. All observers were trained to collect computerized data by the principal investigator or another trained observer. Observers were considered to be trained when they agreed with a trained observer on at least $90 \%$ of responses across two consecutive observations.

Treatment integrity was scored by a third independent observer who was blind to the purpose of the study. Treatment-integrity data were collected via a multi-item checklist that was specific to each condition and phase (see example in Appendix A). Treatment integrity data were collected for $25.0 \%$ of sessions for Keith, $25.5 \%$ of sessions for Wade, and $27.0 \%$ of sessions for Ian. All treatment-integrity data were collected from videos of the sessions. Treatment integrity was, on average, $96.8 \%$ for Ian and $100 \%$ for Wade and Keith.

\section{Procedure}

Functional Analysis (FA). Each child began the experiment with an FA to determine if escaping from the skip-counting task to more preferred academic work functioned as a reinforcer for protesting. The FA consisted of a test condition and a control condition. Sessions were 5 min in duration for each condition. Before each session, the child chose an academic activity from an array of six activities (previously nominated by the teacher to be mastered and relatively preferred) placed equidistant from each other and the child. Functional-analysis sessions continued until rates of protesting were consistently elevated in the test condition relative to the control condition, and each skip-count number was presented at least twice.

During the test condition, the experimenter instructed the child to skip-count by a particular number (3s and 4s for Ian and Wade, 6s and 8s for Keith). We determined the skip- 
count sequence randomly without replacement before the start of the session via a randomizer phone application, but presented each number an equal amount of times to be certain that one did not evoke more challenging behavior than the other. The experimenter instructed the child to count by the number and repeated the instruction every $3 \mathrm{~s}$ if the child was not complying. Following each instance of protesting, the experimenter ceased skip-count demands and allowed 30 s access to the chosen academic activity along with prompts corresponding to the activity and praise from the experimenter. There were no programmed consequences for any other challenging behavior. Following each appropriate request for access to an item that was not present or to leave the session area for any reason, the experimenter said, "that's not available right now,” and redirected the child back to the task. This was to ensure that we were not allowing escape from the task for non-targeted reasons.

During the control condition, the therapist interacted with the child with the chosen academic activity for the duration of the session (identical to the reinforcer intervals in the test condition). There were no programmed consequences for any challenging behavior. Following each appropriate request for access to an item that was not present or to leave the session area for any reason, the experimenter said, "that’s not available right now,” and redirected the child back to the task.

General Procedure. Before the experimental sessions began, the experimenter determined how rapidly each participant could count by ones in a 15-s timing to determine the rate of correct responses the child needed to make during the curricular-revision condition. The experimenter instructed the child to count as high as he could and as quickly, but clearly, as possible while the experimenter timed him. However many numbers the child said without error was set as the goal. For example, if the child correctly said 15 numbers, he would have to make 
at least 15 correct skip-count responses during the curricular-revision condition. If the child correctly said 25 or more numbers, 25 was set as the goal so as to not exceed the number that fluent respondents can typically read in $15 \mathrm{~s}$.

Each session of the experimental manipulation began with the child selecting an academic activity. Six academic activities (same activities from FA) were placed equidistant from each other and the child. The experimenter instructed the child to choose an activity for that session. The experimenter then removed the activities and told the child by which number to skip-count.

Each session consisted of 5, 15-s timings. Each timing was separated by a 15-s intertiming interval. Following each appropriate request for access to an item that was not present or to leave the session area for any reason, the experimenter said, “that's not available right now” and redirected the child back to the task. Sessions were terminated if severe challenging behavior occurred (e.g., highly aggressive behavior or leaving the session area). The experimenter and data collectors responded to severe challenging behavior in accordance with the child's existing behavior intervention plan or other classroom procedures. Only one session had to be terminated. Details are provided in the Results.

Daily sessions were conducted in a series. A series consisted of one session of each of two conditions (DNRA and curricular revision). The order of conditions within a series was randomized without replacement using the same randomizer phone application that was used during the FA. A minimum of one series and a maximum of three series were conducted per day, up to five days per week, depending on the child's availability. A minimum of $1 \mathrm{hr}$ elapsed between series. We conducted, on average, 2.25 series per day for Ian, 2.3 series for Wade, and 2 series for Keith. Most sessions were video recorded. 
A multielement design embedded in a multiple-baseline design was used to demonstrate experimental control. In this design, the two separate conditions were alternately implemented to observe the effects of each condition relative to baseline. Baselines varied in length across participants to ensure that the interventions, rather than time or another extraneous variable, were responsible for behavior change. Conclusions were drawn based on which condition resulted in discriminably lower response rates via visual inspection of graphed data. The experiment began with a baseline phase followed by a treatment phase. Following successful suppression of challenging behavior, an extinction phase was conducted for each treatment. During the extinction phase, treatment was abruptly discontinued (no breaks were provided) to assess potential resurgence.

Baseline. We conducted a baseline phase with each student to confirm that there was no differentiation in the rate of protesting between the two tasks. Baseline levels of responding were also used to later evaluate the extent to which challenging behavior resurged when treatment was abruptly discontinued. We began baseline by asking the child to skip-count by 3 or 4 (or 6 or 8 ) across sessions.

Protesting during the timing resulted in the experimenter ceasing skip-counting demands and providing the child with immediate access to the chosen preferred academic activity for the remainder of the timing and the duration of the subsequent inter-timing interval. If no protesting occurred, the experimenter prompted the child to skip-count every 3 s until time ran out. Then, the experimenter did not provide any attention or activities to the child during the inter-timing interval. If the child skip-counted during the timing and did not protest, the experimenter informed the child of how many correct responses the child made at the end of the timing and provided no further attention during the subsequent inter-timing interval. During the inter-timing 
interval, the experimenter recorded the number of correct answers, whether or not challenging behavior occurred, and reset the counter. These data were collected solely for the purpose of providing feedback, and were not included in the IOA calculations or data-based decisions.

The experimenter instructed the child to count by 3s (or 6s) for at least 6 sessions and by 4 s (or 8 s) for at least 6 sessions (6 series in total). Counting by 3s or 4s (or 6s or 8s) was presented as a series in random order. Once there was no differentiation in the rate of challenging behavior between the two tasks for at least three series, the treatment phase began.

Treatment. There were two treatment procedures implemented for each child following baseline. The skip-count number associated with each treatment (counting by 3s or 4s for Ian and Wade or by 6s or 8s for Keith) was randomly assigned to a condition for each participant. As in baseline, a series consisted of one session of each condition, and the order in which the conditions were presented in the series was randomized.

DNRA with extinction. The experimenter held up a placemat with the number corresponding to that child's DNRA procedure on it and instructed the child to count by that number and repeat the sequence (i.e., 3-36 for 3s, 4-48 for 4s, 6-72 for 6s, 8-96 for 8s) until time ran out. The child was also told that if the task was too difficult, he could work on the preferred activity by saying “please.” The experimenter asked the child to restate the rules, and prompted the child to say "please” if the child did not do so independently. When the child said "please” before the session, the experimenter allowed 30 s of access to the chosen activity to provide contact with the contingency. The experimenter then removed the activity and counted down from 3 to signal the start of the session.

During timings, the experimenter prompted the child to skip-count following every 3 s of non-responding. Immediately after the child said "please," the experimenter ceased skip- 
counting prompts, said, “let’s keep working on this,” and provided access to the preferred activity for the remainder of the timing and the subsequent inter-timing interval. There were no programmed consequences for challenging behavior (including protesting) or correct skipcounting responses. However, the experimenter told the child the number of correct responses, if applicable, immediately following each timing (during the inter-timing interval). In the last $3 \mathrm{~s}$ of the inter-timing interval, the experimenter counted down from 3 before removing the preferred activity and resuming prompts to skip-count.

Curricular revision without extinction. For the curricular-revision condition, the experimenter held up a placemat with the number corresponding to that child's curricularrevision procedure on it. The experimenter instructed the child to count by that number and repeat the sequence (i.e., 3-36 for 3s, 4-48 for 4s, 6-72 for 6s, 8-96 for 8 s) until time ran out. The experimenter informed the child that if he made at least the required number of correct responses (determined during the count-by-ones probe), he could have more time with the chosen item by skipping the next timing. He was also instructed to use his list if the task was too difficult. The experimenter provided the child with a list containing the correct skip-count sequence until the list was eventually removed.

We would have faded out the numbers on the list by removing a number from the list and replacing it with a blank square as the child mastered each teaching step (an example of the sequence of removed numbers is provided in Appendix B). We considered a step to be mastered if the child made at least the required number of correct responses determined during the countby-ones probe during 3 of the 5 timings in a session with at least $90 \%$ overall accuracy. When a new step was introduced, we planned for the experimenter to introduce the step by writing in the missing numbers with a dry erase marker and instructing the child to read the list prior to the 
start of the session. The experimenter would then erase the numbers and explain to the child that he must remember the missing numbers when he counts. This never occurred, however, because the fading procedure was not necessary for any participant. For the terminal teaching step of the curricular-revision condition, the list was not provided, and only the placemat with the number corresponding to the curricular-revision condition for that child was present. The terminal step would have been probed after every other step was mastered (i.e., after steps 1, 3, 5, 7, 9, and 11). This probe consisted of a 15-s timing with only the placemat present. If the child met the mastery criteria during this probe, subsequent sessions consisted of the terminal step. If he did not meet mastery during the probe, the therapist would continue on with the next step after the step he most recently mastered. Each participant met the mastery criteria during the first terminal probe. If the child was attempting to skip-count but was not meeting mastery during at least one timing across at least two sessions, we further simplified the task.

The experimenter counted down from 3 to signal the start of the session. During the timing, the experimenter prompted the child to skip-count following every $3 \mathrm{~s}$ of nonresponding. If the child made at least the required number of correct responses determined during the count-by-ones probe in a timing, the experimenter said, "let's keep working on this" and delivered the preferred activity when the timing was complete. The experimenter informed the child of the number of correct responses he made and that he could skip the next timing. This feedback was enthusiastic and would often include praise statements and high fives. During the break, the child was allowed to work on the preferred activity during the inter-timing interval as well as the duration of the next timing and its inter-timing interval (45 s total). If the protested during the timing, the experimenter immediately ceased skip-count prompts, said, “let’s keep working on this,” and allowed access to the preferred activity for the remainder of the timing and 
the subsequent inter-timing interval (up to $30 \mathrm{~s}$ ). Extinction was not in place for protesting to further distinguish curricular revision and DNRA, and to evaluate the extent to which consequence manipulations are a necessary part of curricular revision. In the last $3 \mathrm{~s}$ of the intertiming interval before the removal of the preferred activity, the experimenter counted down from 3 before removing the activity and resuming prompts to skip-count. There were no programmed consequences for non-targeted challenging behavior.

Curricular revision with extinction. If protesting did not suppress in the curricularrevision condition, extinction of target challenging behavior was added. This condition was implemented identically to the above curricular-revision condition, except that the experimenter continued to prompt the child to skip-count following protesting rather than allowing access to the preferred activity.

Extinction Phase. The experimenter conducted extinction sessions identically to the sessions in the treatment phase, except that the experimenter did not provide breaks with the preferred activity, regardless of behavior. The experimenter continued to inform the child of the number of correct responses. This phase assessed the extent of resurgence of protesting when breaks contingent on condition-specific verbal responses (i.e., skip-counting or break requests) were not provided.

\section{Results}

Figure 1 depicts the rate of protesting during each condition of the FA conducted by the experimenters for each participant. The skip-count demand is represented by the number above each “Test” data point. Each participant protested substantially more during the test condition relative to the control condition. There was no clear differentiation across skip-count demands. 
This indicates that escaping from skip-count demands to work on a mastered academic task with an adult functioned as a reinforcer for protesting for each participant.

Figures 2, 3, 4, and 5 are graphed in a multiple-baseline design to demonstrate experimental control. Figure 2 depicts the rates of protesting for all participants across phases and conditions. For Ian, whose data appear in the top graph, protesting was high and largely undifferentiated across conditions during baseline ("BL” on graph). Both the DNRA and curricular-revision conditions suppressed behavior about equally during the treatment phase. There was some variability within each condition, but responding was eliminated in both conditions by the end of the phase. During the extinction phase, responding did not resurge following either condition. The final session had to be terminated after 1 min $19 \mathrm{~s}$, however, because Ian left the session area (depicted on graphs by asterisk).

For Wade, whose data appear in the middle graph, protesting was high and largely undifferentiated across conditions during baseline. Initially during the treatment phase, DNRA resulted in lower rates of protesting than curricular revision. Thus, extinction was implemented for protesting during curricular revision. Following this change (noted by the dotted phasechange line on the graph), protesting was eliminated during both conditions. Protesting was initially suppressed during both conditions at the start of the treatment phase (prior to implementing extinction for protesting during curricular revision), but increased again as the phase went on. Once extinction for protesting was implemented during curricular revision, we kept Wade in treatment to ensure that this pattern of responding was not occurring again and that the treatments were truly suppressing protesting. During the extinction phase, a substantial amount of resurgence occurred following DNRA, but no resurgence occurred following curricular revision. 
For Keith, whose data appear in the bottom graph, protesting was high and largely undifferentiated across conditions during baseline. Initially during the treatment phase, DNRA resulted in lower rates of protesting than curricular revision, similar to Wade. We implemented extinction for protesting during curricular revision for Keith as well. Following this change, (noted by the dotted phase-change line on the graph), protesting was eliminated during curricular revision only. During the extinction phase, resurgence occurred following both conditions nearly equally. We implemented the curricular revision treatment with extinction for protesting to suppress Keith’s protesting again following this high amount of resurgence (“Treatment” on Keith’s graph). Responding was again suppressed when we implemented curricular revision.

Figure 3 depicts the total number of correct academic responses made by each participant across phases and conditions. Ian made zero correct responses, regardless of condition, during the baseline phase. He continued to make nearly zero correct responses during each session of the DNRA condition of the treatment phase. Ian's total correct responses were high during each session of the curricular-revision condition of the treatment phase. Ian reached the terminal step (depicted by the triangle on the graph) after the first probe, which occurred following 9 sessions of curricular revision (see Table 2 for probe data). During the curricular-revision condition of the extinction phase, Ian engaged in a "burst” of academic responding. In other words, he made substantially more correct academic responses when treatment with curricular revision was discontinued. Correct academic responding continued to remain near zero following treatment with DNRA, although he did engage in some correct academic responding.

Wade also made zero correct responses, regardless of condition, during the baseline phase. He continued to make nearly zero correct responses during each session of the DNRA condition of the treatment phase. Before we implemented extinction for protesting during the 
curricular-revision condition, there was a lot of variability in the number of correct responses. This seemed to be related to whether or not he was engaging in high levels of protesting during that session. In other words, if he protested, the skip-count demands ceased, and thus the opportunity to make correct responses ceased. If he did not protest during the session, he tended to make more correct responses. Even when he was making correct academic responses, Wade was still not reaching his aim during any of the timings. Because of this, we initially believed that Wade was having trouble acquiring the skill due to the component still not being small enough. We tried breaking the task down further by teaching him to attend to the place value of two-digit numbers using flashcards rather than the list (sessions 19-28), teaching him to attend to place value using the list (sessions 29-44), and adjusting the aim based on Wade's performance (sessions 46-61). Once we realized that the issue was due to Wade's protesting interfering with acquisition, we implemented extinction for his protesting and reverted back to the original curricular-revision procedure. When extinction was implemented for Wade’s protesting, he continually engaged in high levels of correct academic responding. Wade reached the terminal step (depicted by the triangle on the graph) after the first probe, which occurred following 33 sessions of curricular revision (see Table 2 for probe data). We saw a "burst" of academic responding during the curricular-revision condition of the extinction phase and a small increase during DNRA, similar to Ian.

Keith also made zero correct responses during the baseline phase, regardless of condition. He continued to make nearly zero correct responses during each session of the DNRA condition of the treatment phase. Keith engaged in high levels of correct academic responding during each session of the curricular-revision condition during the treatment phase, regardless of whether extinction was implemented for protesting. He did, however, make substantially more correct 
responses during the curricular-revision condition when extinction was implemented for protesting. Keith reached the terminal step (depicted by the triangle on the graph) after the first probe, which occurred following 18 sessions of curricular revision (see Table 2 for probe data). We also saw a "burst" of academic responding during the curricular-revision condition of the extinction phase and a small increase during DNRA, similar to Ian and Wade.

Figure 4 depicts the percentage of accurate responses made by each participant across phases and conditions. Ian did not engage in any correct responses, and, thus, did not engage in accurate responding, during either condition of the baseline phase. When Ian made correct responses during the DNRA condition of the treatment phase, accuracy never exceeded 50\%. During the curricular-revision condition, however, accuracy was always above 90\%. During the curricular-revision condition of the extinction phase, accuracy still remained above $90 \%$. Accuracy increased slightly during one session of the DNRA condition, but did not exceed 60\%. Wade also did not engage in any correct responses, and, thus, did not engage in accurate responding during either condition of the baseline phase. When Wade made correct responses during the DNRA condition of the treatment phase, accuracy was typically high. This was due to Wade making very few total responses. As with the total number of correct responses, accuracy was variable during the curricular-revision condition of the treatment phase before extinction was implemented for protesting. Once extinction was implemented for protesting, accuracy increased above $90 \%$ for all but one session of curricular revision. During the extinction phase, accuracy remained high during the curricular-revision condition, and was only high during one session of the DNRA condition. Again, this was due to Wade making very few total responses.

Keith engaged in correct responding during one session of curricular revision and one session of DNRA during the baseline phase. Accuracy was $100 \%$ and $75 \%$, respectively, but 
Keith engaged in very little total responses. During the treatment phase, accuracy was mostly low during the DNRA condition. Accuracy was always above $90 \%$ for the curricular-revision condition, regardless of whether extinction was in place for protesting. During the extinction phase, accuracy decreased as the phase progressed during the curricular-revision condition. Accuracy was at zero for the entire extinction phase during the DNRA condition. Once we reinstated treatment following the extinction phase, accuracy increased to $100 \%$ during the curricular-revision condition.

Figure 5 depicts the percentage of the session on break for all participants across phases and conditions. The percentage of the session on break was high and largely undifferentiated across conditions during the baseline phase for all participants. Ian spent substantially more time on break during DNRA sessions than during curricular-revision sessions for the treatment phase. As he acquired the skip-counting skill during the curricular-revision condition, the percentage of time on break increased and eventually remained stable, but was still lower than the percentage of time on break during the DNRA condition. Additionally, when Ian met the terminal step during curricular revision (depicted on the graphs by the triangle), the amount of time on break during the subsequent DNRA session decreased dramatically, seemingly because Ian was attempting to make correct responses rather than saying, “please.”

Wade initially spent more time on break during DNRA than during curricular revision in the treatment phase. As he began to protest during curricular-revision sessions, however, he spent nearly equal amounts of time on break, regardless of condition. Once we implemented extinction for Wade's protesting in the curricular-revision condition, he spent less time on break during this condition than during the DNRA condition. 
Keith always spent less time on break during the curricular-revision condition than during the DNRA condition of the treatment phase, but this difference was exaggerated once extinction was implemented for protesting during curricular revision. There were no breaks provided during the extinction phase, and, thus, no participant spent any amount of the session on break, regardless of condition.

\section{Discussion}

We evaluated the relative efficacy of curricular revision and DNRA for escapemaintained challenging behavior with verbally competent children. We also evaluated relative resurgence when the interventions were abruptly discontinued. For one participant, Ian, curricular revision was as effective as DNRA at reducing challenging behavior. For two participants, Wade and Keith, extinction for the target behavior was necessary to make curricular revision as effective as DNRA. All participants made more correct academic responses and spent more time working on the skip-count task during curricular revision than during DNRA. Our results provide evidence for the recommendations made by Geiger and colleagues (2010) to implement curricular revision as a treatment for escape-maintained behavior. Our results also add to the existing literature that indicates that curricular revision is a viable treatment option for challenging behavior (e.g., Dunlap et al., 1991; McComas et al., 2000; Winterling et al., 1987).

Although there are a variety of learner-specific procedures within curricular revision, the procedures that we used in our study involved short durations of the task, similar to Dunlap et al., (1991), and involved a list of the skip-count sequence to facilitate completion of the task, similar to McComas et al., (2000). Our results also add to the existing literature because our curricularrevision procedures involved facilitating learning via fluency timings. Future research should 
evaluate the efficacy of other curricular-revision procedures when comparing treatments for challenging behavior.

In addition to being efficacious, curricular revision may be a more socially valid intervention for parents and teachers because students spent more time working on difficult tasks during curricular revision than DNRA. One potential drawback to the social validity of curricular revision is that it may be more effortful to implement than DNRA due to the necessity to make materials and assess which component skills are lacking for any given composite skill. One potentially effortful component of our curricular-revision procedure was our planned gradual fading of the numbers on the list until the child could skip-count without the list. We demonstrated, however, that this stimulus-fading procedure was not necessary. Each participant was able to accurately and fluently perform the skip-count task after learning the first step. Thus, for certain tasks, excess materials and preparation time may not be necessary and may therefore not reduce the social validity of curricular revision. Curricular revision may also be more socially valid for the students. Anecdotally, each of our participants showed enthusiasm following mastery of the task during curricular revision. After the session, they sometimes asked their teachers or parents to listen to them skip count. Because the participants engaged in escapemaintained challenging behavior, this enthusiasm for learning a new skill is encouraging. It can not only be rewarding for teachers and parents to see the student engage with academics, but it may also allow the students to contact additional social reinforcers that may make participation in other forms of academic instruction more fun for the participant. Future research should formally assess the social validity of both procedures when comparing treatment procedures. Response effort required for implementation of DNRA may also be a consideration. As previously mentioned, DNRA procedures are typically introduced by reinforcing every instance 
of the appropriate alternative response and later thinning the reinforcement schedule (e.g., Greer, et al., 2016; Hagopian, et al., 2011; Tiger et al., 2008), which can be very effortful and time consuming. Thinning reinforcement schedules can result in periods of localized extinction, which can cause resurgence of the target response (e.g., Volkert et al., 2009). This may not occur with curricular revision, particularly when it is implemented solely as an antecedent procedure. Even when resurgence was a concern following treatment with curricular revision, as it was with Keith, it was never greater than the resurgence observed following treatment with DNRA. We did not explicitly schedule thin during our DNRA procedure. Future research should compare the efficacy of the treatment procedures and potential subsequent resurgence when the schedule of reinforcement is thinned for either procedure.

Resurgence is a robust phenomenon following differential reinforcement procedures (e.g., Lattal \& St. Peter Pipkin, 2009). We did not, however, consistently observe resurgence following abrupt discontinuation of differential reinforcement in our study. It is unclear why it did not reliably occur, although the continued feedback of the number of correct responses may have played some role. Future research should evaluate the conditions necessary to produce as well as mitigate resurgence when comparing DNRA and curricular revision.

Resurgence of the target response did not occur following either condition for Ian. Anecdotally, however, he did engage in other challenging behaviors during the extinction phase, such as banging the table, leaving his area, and cursing. It is possible that they were part of a response-class hierarchy that also included protesting. A response-class hierarchy is one in which behaviors that are functionally similar but topographically distinct tend to occur in a certain order (Beavers, Iwata, \& Gregory, 2014). Response-class hierarchies can resurge following the cessation of positive reinforcement (e.g., Lieving, Hagopian, Long, \& O’Connor, 2004). Future 
research should explicitly measure increases in non-targeted responses during extinction following the termination of these two treatments, especially in the context of response-class hierarchies.

Extinction for protesting during our treatments might have been an important component of our interventions and warrants further evaluation. Curricular revision without extinction for protesting was effective for Ian. This form of curricular revision was distinct from DNRA, which always included extinction for protesting. Curricular revision required an additional escapeextinction component to suppress challenging behavior for Wade and Keith, however. It is unclear what components of curricular revision were sufficient in suppressing challenging behavior for Ian without necessitating escape extinction, but were not sufficient for Wade and Keith. Interestingly, we did not observe initially high rates of protesting (an "extinction burst”) when we implemented escape extinction during curricular revision. This could have been due to the pre-session instructions that indicated to the participants how they could earn their break. The lack of clear extinction bursts may mean that implementing escape extinction with curricular revision would not be a difficult addition to the procedure in practice. Regardless of this, escape extinction still may not always be possible. Thus, clinicians could benefit from curricularrevision procedures that do not rely on escape extinction, but rely on decreasing or eliminating the reinforcing value of escaping from the task (i.e., abolishing the establishing operation). Future research should evaluate what other manipulations are necessary to completely abolish the establishing operation and avoid having to implement escape extinction.

Another factor that may have influenced whether escape extinction was necessary during curricular revision is the delay to reinforcement during curricular revision relative to DNRA. This is particularly relevant for children with ADHD, such as the participants in the current 
study, because impulsivity and self-control issues tend to be a diagnostic symptom of ADHD (American Psychiatric Association, 2013). Neef, Bicard, and Endo (2001) demonstrated ways to increase self-control in children with ADHD. The authors accomplished this by assessing which other dimensions of a reinforcer (e.g., reinforcer quality, reinforcer rate, response effort) would compete with the immediacy of the reinforcer and result in the child making the self-controlled response. To increase the frequency of the self-controlled response (choosing the larger, later reinforcer over the smaller, sooner reinforcer), the authors manipulated the dimensional qualities of the reinforcer that was delivered at a delay and also gradually increased the delay to that reinforcer. Athens and Vollmer (2010) demonstrated procedures to reduce challenging behavior and increase appropriate behavior without implementing extinction for the target behavior also by manipulating dimensions of the reinforcer. The authors manipulated the duration of reinforcement, the quality of the reinforcer, the delay to reinforcement, and a combination of all three dimensions to be richer following appropriate behavior than following challenging behavior. The authors saw the greatest effect following manipulation of all three dimensions of reinforcement. Based on the results obtained by Neef et al., (2001) and Athens and Vollmer (2010), it is possible that we could have obtained different results in our study if we would have manipulated dimensions of the delayed reinforcer during the curricular-revision condition without escape extinction. Future research should assess the effects of consequence-manipulation procedures when comparing curricular revision with DNRA.

We selected skip counting as the task for each participant because two skip-count sequences were similar enough to use for each condition, but distinct enough that learning one sequence would not influence learning the other. We also chose skip counting because each participant had the necessary component skills (e.g., reading numbers) to perform the task. There 
was nothing inherent to skip counting to evoke challenging behavior for our participants; each participant tended to engage in challenging behavior to escape from any difficult academic task. Because we used skip counting as the task for each participant, it is unclear whether our results would have been different with a different task. It is likely, however, that any skill could be taught with curricular revision as long as it is broken into its components. Additionally, we conducted our study with typically developing students who had previous experience with fluency timings and were receiving behavior-analytic services. Future research should evaluate the generality of the procedure with other tasks, populations, and participants without experience with fluency timings.

There were some notable limitations to our study. Because protesting resulted in escape from skip-count demands during the baseline phase, we were not able to explicitly measure any participant's baseline levels of performance for either skip-count sequence. Thus, we could not evaluate whether curricular revision improved acquisition relative to DNRA. Future research should design baseline conditions to be able to explicitly evaluate acquisition between the two treatments. Additionally, each of our participants had at least one clinical diagnosis and was taking medication as a treatment. We did not have access to their medical records, and were thus unsure of which medications they were on or when they were taking them. Some of the participants' parents also reported that the medications or the timing of administration were not always consistent. It is unclear whether these inconsistencies influenced our results, especially when there was variability in responding. Future research should evaluate the role of medication in comparing behavioral treatments and in assessing academic responding. 


\section{References}

American Psychiatric Association. (2013). Diagnostic and statistical manual of mental disorders (5th ed.). Arlington, VA: American Psychiatric Publishing.

Asmus, J. M., Ringdahl, J. E., Sellers, J. A., Call, N. A., Andelman, M. S., \& Wacker, D. P. (2004). Use of a short-term inpatient model to evaluate aberrant behavior: Outcome data summaries from 1996 to 2001. Journal of Applied Behavior Analysis, 37, 283-304. doi:10.1901/jaba.2004.37-283

Beavers, G. A., Iwata, B. A. and Gregory, M. K. (2014). Parameters of reinforcement and response-class hierarchies. Journal of Applied Behavior Analysis, 47, 70-82. doi:10.1002/jaba.102

Beavers, G. A., Iwata, B. A., \& Lerman, D. C. (2013). Thirty years of research on the functional analysis of challenging behavior. Journal of Applied Behavior Analysis, 46, 1-21. doi:10.1002/jaba.30

Carr, E. G., \& Durand, V. M. (1985). Reducing behavior challengings through functional communication training. Journal of Applied Behavior Analysis, 18, 111-126. doi:10.1901/jaba.1985.18-111

Doughty, A.H., daSilva, S.P, \& Lattal, K.A. (2007). Differential resurgence and response elimination. Behavioural Processes, 35, 115-128. doi:10.1016/j.beproc.2007.02.025

Dunlap, G., \& Kern, L. (1996). Modifying instructional activities to promote desirable behavior: A conceptual and practical framework. School Psychology Quarterly, 11, 297-312. doi:10.1037/h0088936 
Dunlap, G., Kern-Dunlap, L., Clarke, S., \& Robbins, F. R. (1991). Functional assessment, curricular revision, and severe behavior challenges. Journal of Applied Behavior Analysis, 24, 387-397. doi:10.1901/jaba.1991.24-387

Geiger, K. B., Carr, J. E., \& LeBlanc, L. (2010). Function-based treatments for escape maintained challenging behavior: A treatment-selection model for practicing behavior analysts. Behavior Analysis in Practice, 3, 22-32.

Greer, B. D., Fisher, W. W., Saini, V., Owen, T. M., \& Jones, J. K. (2016). Functional communication training during reinforcement schedule thinning: An analysis of 25 applications. Journal of Applied Behavior Analysis, 49, 105-121. doi:10.1002/jaba.265

Hagopian, L. P., Boelter, E. W., \& Jarmolowicz, D. P. (2011). Reinforcement schedule thinning following functional communication training: Review and recommendations. Behavior Analysis in Practice, 4, 4-16.

Iwata, B. A., Dorsey, M. F., Slifer, K.J., Bauman, K. E., \& Richman, G. S. (1994). Toward a functional analysis of self-injury. Journal of Applied Behavior Analysis, 27, 197-209. (Reprinted from Analysis and Intervention in Developmental Disabilities, 2, 3-20).

Johnson, K. R., \& Layng, T. J. (1992). Breaking the structuralist barrier: Literacy and numeracy with fluency. American Psychologist, 47, 1475-1490. doi:10.1037/0003-066X.47.11.1475

Johnson, K. R., \& Layng, T. J. (1996). On terms and procedures: Fluency. The Behavior Analyst, 19, 281-288.

Johnson, K., \& Street, E. M. (2013). Response to intervention and precision teaching: Creating synergy in the classroom. New York, NY, US: Guilford Press. 
Lalli, J. S., Casey, S., \& Kates, K. (1995). Reducing escape behavior and increasing task completion with functional communication training, extinction, and response chaining. Journal of Applied Behavior Analysis, 28, 261-286. doi:10.1901/jaba.1995.28-261

Lieving, G. A., Hagopian, L. P., Long, E. S., \& O'Connor, J. (2004). Response-Class Hierarchies and Resurgence of Severe Problem Behavior. The Psychological Record, 54, 621-634. doi: 10.1007/BF03395495

Lieving, G. A., \& Lattal, K. A. (2003). Recency, repeatability, and reinforcer retrenchment: An experimental analysis of resurgence. Journal of the Experimental Analysis of Behavior, 80, 217-233. doi: 10.1901/jeab.2003.80-217.

Lennox, D. B., Miltenberger, R. G., Spengler, P., \& Efranian, N. (1988). Decelerative treatment practices with persons who have mental retardation: A review of five years of the literature. American Journal on Mental Retardation, 92, 492-501.

Marsteller, T. M., \& St. Peter, C. C. (2012). Resurgence during treatment challenges. Revista Mexicana de Análisis de la Conducta, 38, 7-23.

Marsteller, T. M., St. Peter, C. C. (2014). Effects of fixed-time reinforcement schedules on resurgence of challenging behavior. Journal of Applied Behavior Analysis, 47, 455-469. doi:10.1002/jaba.134

McComas, J., Hoch, H., Paone, D., \& El-Roy, D. (2000). Escape behavior during academic tasks: A preliminary analysis of idiosyncratic establishing conditions. Journal of Applied Behavior Analysis, 33, 479-493. doi:10.1901/jaba.2000.33-479

Neef, N. A., Bicard, D. F., \& Endo, S. (2001). Assessment of impulsivity and the development of self-control in students with attention deficit hyperactivity disorder. Journal of Applied Behavior Analysis, 34, 397-408. doi:10.1901/jaba.2001.34-397 
Petscher, E. S., Rey, C., \& Bailey, J. S. (2009). A review of empirical support for differential reinforcement of alternative behavior. Research in Developmental Disabilities, 30, 409425. doi: 10.1016/j.ridd.2008.08.008

Singer, G. H., Singer, J., \& Horner, R. H. (1987). Using pretask requests to increase the probability of compliance for students with severe disabilities. Journal of the Association for Persons with Severe Handicaps, 12, 287-291.

Smith, R. G., Iwata, B. A., Goh, H., \& Shore, B. A. (1995). Analysis of establishing operations for self-injury maintained by escape. Journal of Applied Behavior Analysis, 28, 515-535. doi:10.1901/jaba.1995.28-515

Lattal, K. A., \& St. Peter Pipkin, C. (2009). Resurgence of previously reinforced responding: Research and application. The Behavior Analyst Today, 10, 254-266. doi:10.1037/h0100669

Volkert, V. M., Lerman, D. C., Call, N. A., \& Trosclair-Lasserre, N. (2009). An evaluation of resurgence during treatment with functional communication training. Journal of Applied Behavior Analysis, 42, 145-160. doi:10.1901/jaba.2009.42-145

Vollmer, T. R., and Iwata, B. A. (1992). Differential reinforcement as treatment for behavior disorders: Procedural and functional variations. Research in Developmental Disabilities, 13, 393-417. doi:10.1016/0891-4222(92)90013-V

Vollmer, T. R., Roane, H. S., Ringdahl, J. E., Marcus, B. A. (1999). Evaluating treatment challenges with differential reinforcement of alternative behavior. Journal of Applied Behavior Analysis, 32, 9-23.

Wacker, D. P., Steege, M. W., Northrup, J., Sasso, G., Berg, W., Reimers, T., Cooper, I., Cigrand, K. \& Donn, I. (1990) A component analysis of functional communication 
training across three topographies of severe behavior challengings. Journal of Applied Behavior Analysis, 23, 417-429.

Winterling, V., Dunlap, G., \& O'Neill, R. E. (1987). The influence of task variation on the aberrant behaviors of autistic students. Education \& Treatment of Children, 10, 105-119. 
Table 1

Average IOA Score for Each Response for All 3 Participants

\begin{tabular}{|c|c|c|c|c|c|}
\hline Participant & Protest & Correct Response & Incorrect Response & Break Request & $\underline{\text { Break }}$ \\
\hline Ian & $97.7 \%$ & $98 \%$ & $96.2 \%$ & $97.7 \%$ & $93.6 \%$ \\
\hline Wade & $98.3 \%$ & $95.7 \%$ & $98.2 \%$ & $99.2 \%$ & $96.7 \%$ \\
\hline Keith & $97.4 \%$ & $98.7 \%$ & $98.8 \%$ & $98.8 \%$ & $93.4 \%$ \\
\hline
\end{tabular}


Table 2

Data from Terminal-Step Probe for All 3 Participants

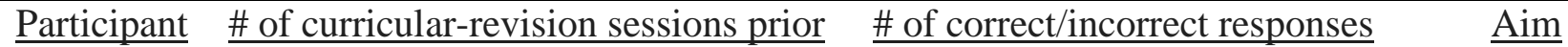

Ian

9

$28 / 0$

25

Wade

33

$20 / 0$

18

Keith

18

$37 / 0$

25 

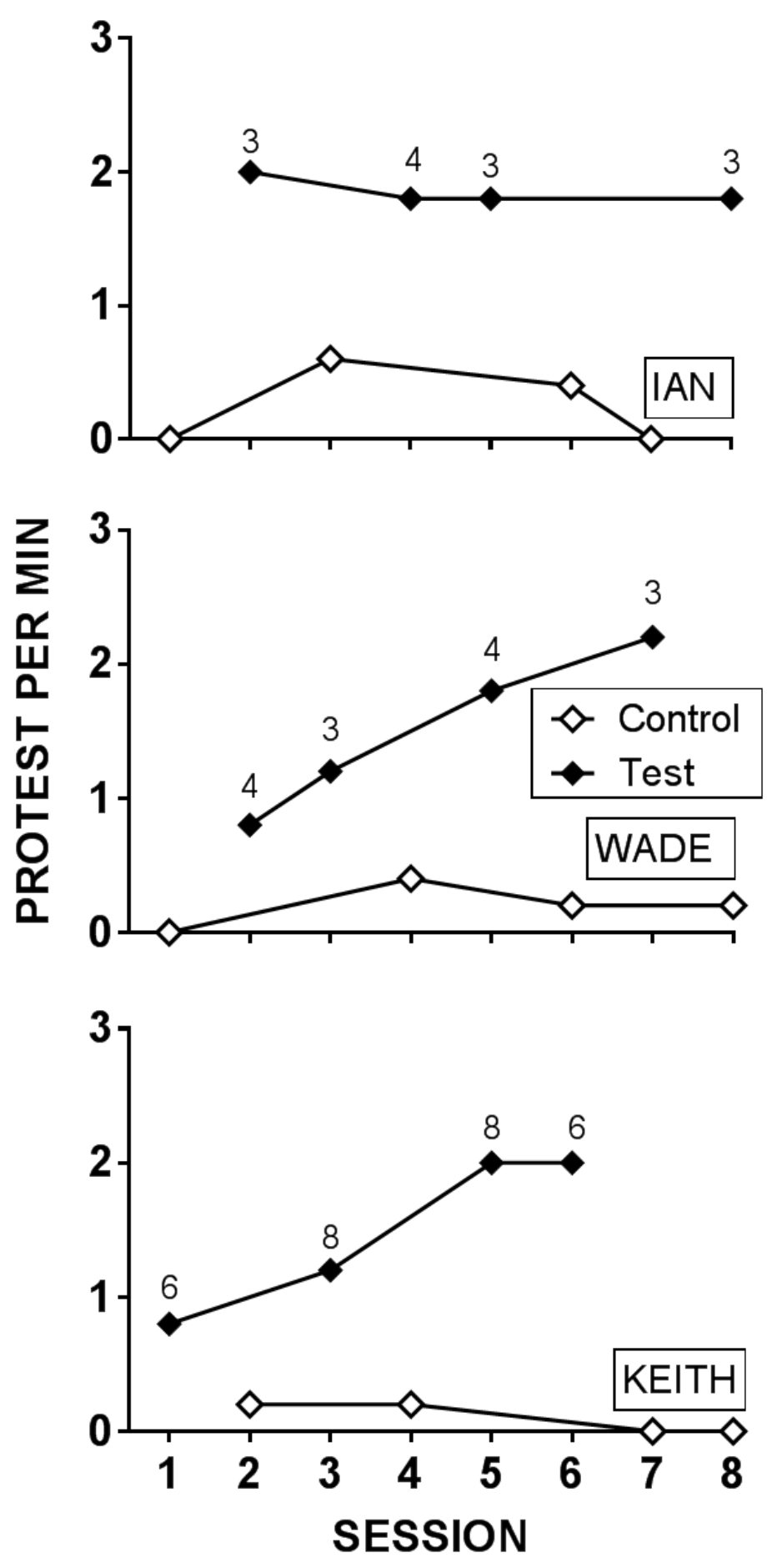

Figure 1. Protest per min during each session of the experimenter-conducted FA for each participant. The numbers above the test data path indicate the skip-count number. 


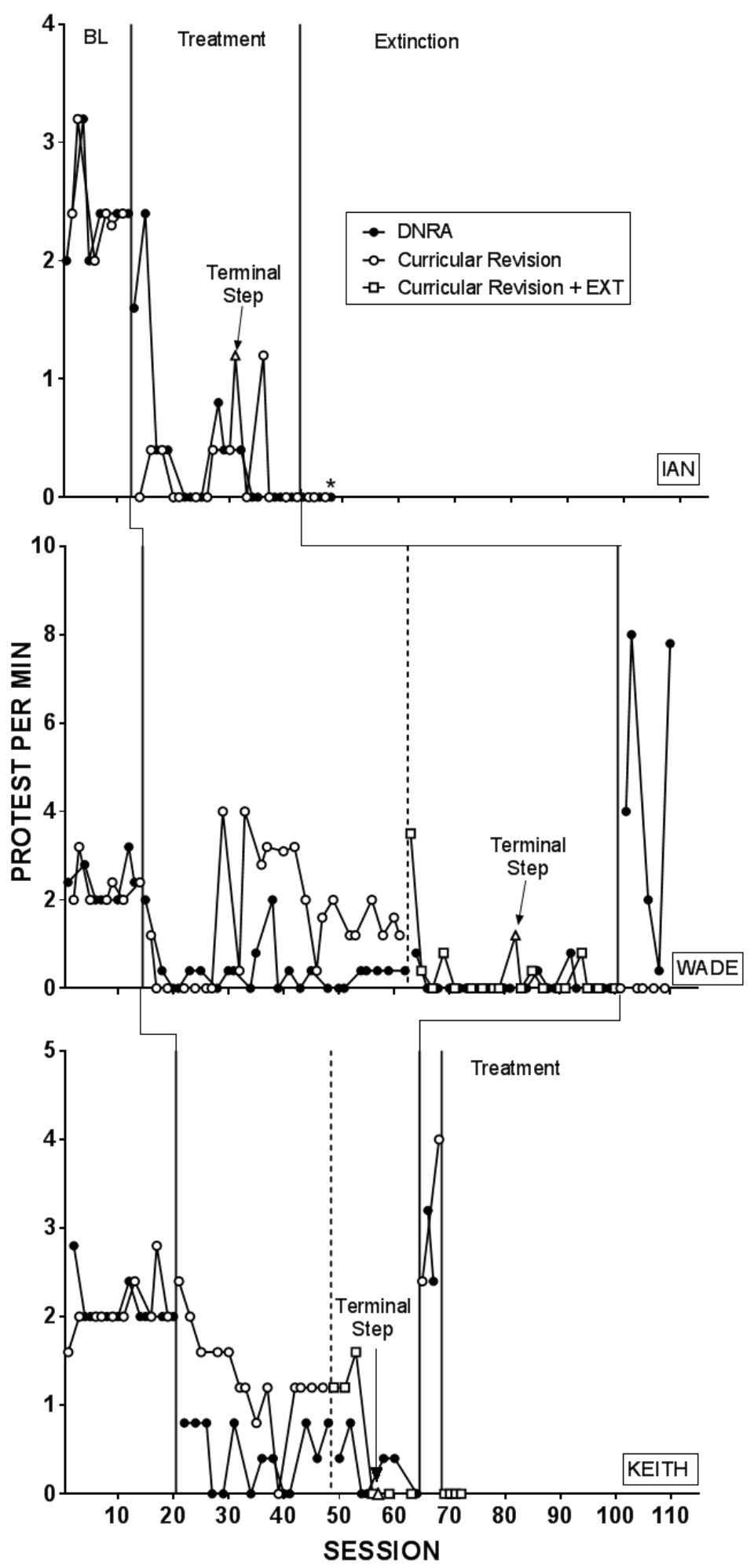

Figure 2. Protest per minute during DNRA and curricular-revision conditions of the baseline, treatment, and extinction phases for all three participants. The asterisk denotes the terminated session. 


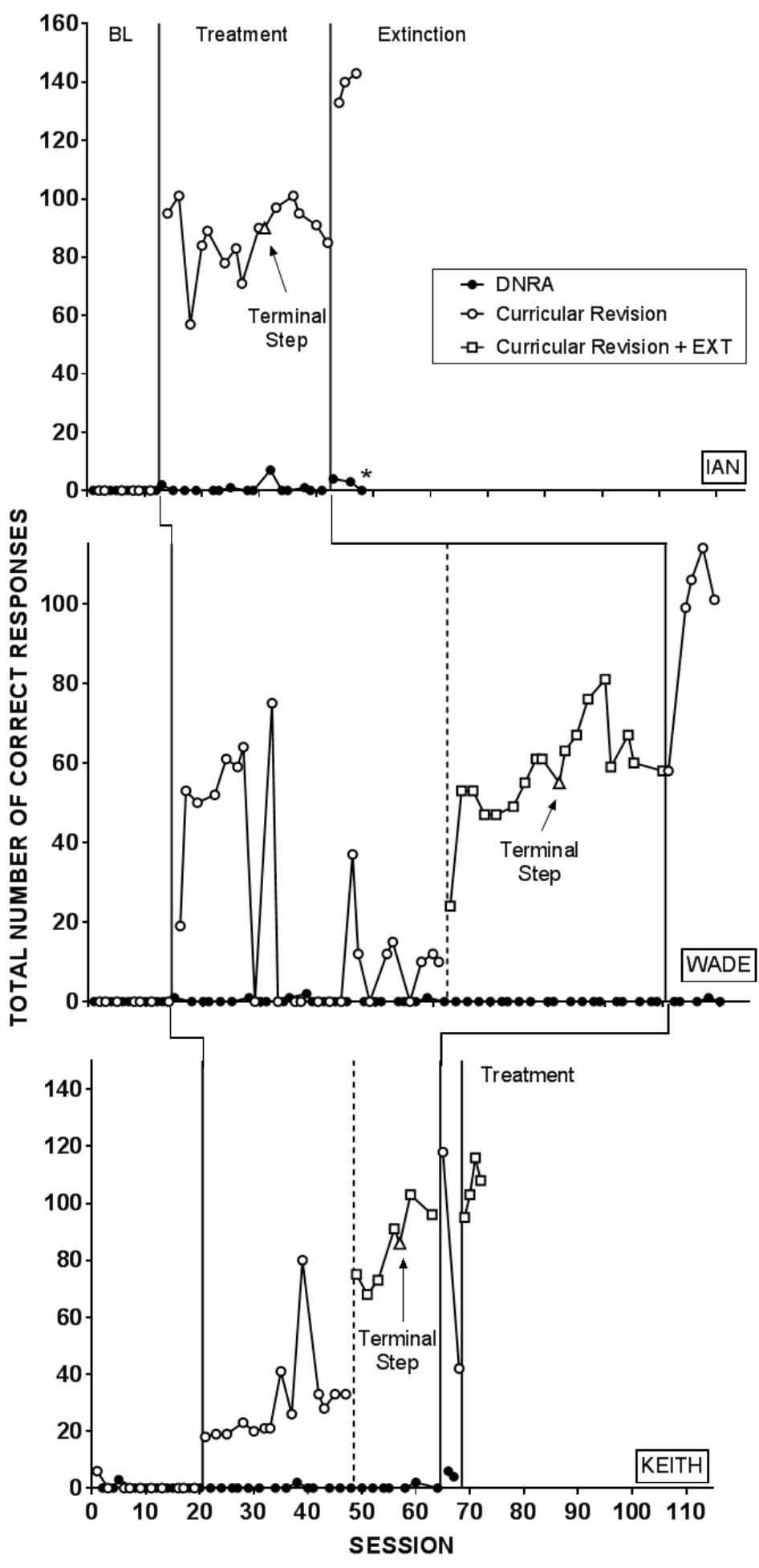

Figure 3. Total number of correct responses during DNRA and curricular-revision conditions of the baseline, treatment, and extinction phases for all three participants. The asterisk denotes the terminated session. 


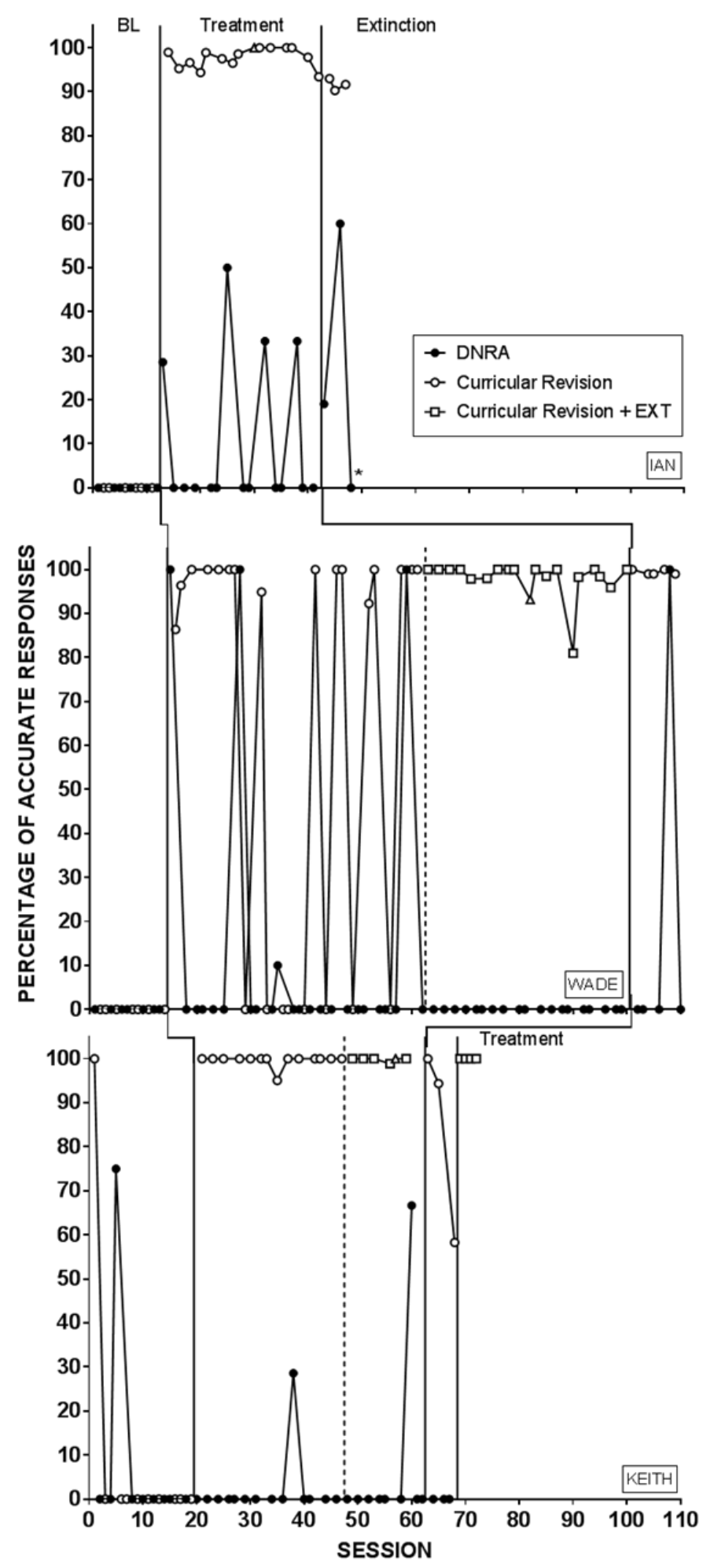

Figure 4. Percentage of accurate responses during DNRA and curricular-revision conditions of the baseline, treatment, and extinction phases for all three participants. The asterisk denotes the terminated session. 


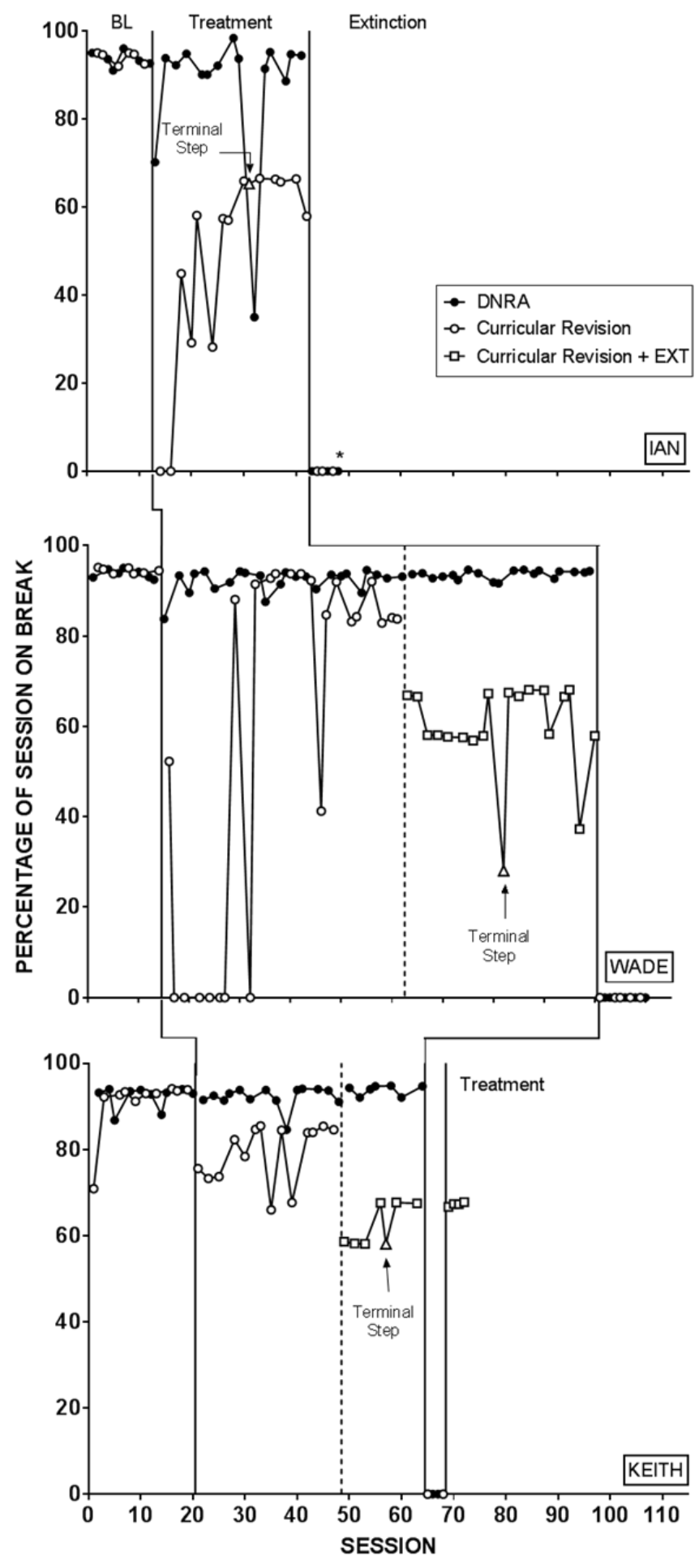

Figure 5. Percentage of session on break during DNRA and curricular-revision conditions of the baseline, treatment, and extinction phases for all three participants. Note that the asterisk denotes the terminated session. 


\title{
Appendix A
}

\author{
Treatment Integrity Checklist for DNRA Sessions
}

Student__LR Thesis Tx INT Skip count \#__ DNRA IOA Prim
Session __
Session was 2.5 min in duration
Session consisted of 5 timings
Therapist responds to appropriate requests by saying it's not
available or telling the child when it will be available
Correct SD in place
Child informed of contingency before start of session

Therapist counts down (3..2..1) before the start of each timing:

\begin{tabular}{|c|c|}
\hline Correct & Incorrect \\
\hline & \\
\hline
\end{tabular}

Therapist delivers correct demand (count by 3's or 4's - or - say the numbers)

\begin{tabular}{|c|c|}
\hline Correct & Incorrect \\
\hline & \\
\hline
\end{tabular}

Timings were $15 \mathrm{~s}$ in duration $(+/-2 \mathrm{~s})$

\begin{tabular}{|c|c|}
\hline Correct & Incorrect \\
\hline & \\
\hline
\end{tabular}

Inter-timing intervals were $15 \mathrm{~s}$ in duration $(+/-2 \mathrm{~s})$

\begin{tabular}{|c|c|}
\hline Correct & Incorrect \\
\hline & \\
\hline
\end{tabular}

Therapist immediately delivers chosen preferred activity following target behavior for remainder of timing + entire inter-timing interval (reinforcer interval)

\begin{tabular}{|c|c|c|}
\hline Correct & Incorrect & \multirow{2}{*}{ N/A } \\
\hline & & \\
\hline
\end{tabular}

Therapist interacts with child during reinforcer interval

\begin{tabular}{|c|c|c|}
\hline Correct & Incorrect & \multirow{2}{*}{ N/A } \\
\hline & & \\
\hline
\end{tabular}

Therapist does not interact with child during inter-timing interval if no target behavior occurs

\begin{tabular}{|c|c|c|}
\hline Correct & Incorrect & N/A \\
\hline & & \\
\hline
\end{tabular}

Notes: 


\section{Appendix B}

Curricular Revision Stimulus-Fading Steps for 3s

$\begin{array}{llllllllllll}3 & 6 & 9 & 12 & 15 & 18 & 21 & 24 & 27 & 30 & 33 & 36\end{array}$

$\begin{array}{llllllllllll}3 & \square & 9 & 12 & 15 & 18 & 21 & 24 & 27 & 30 & 33 & 36\end{array}$

$\begin{array}{llllllllllll}3 \quad \square \quad \square & 12 & 15 & 18 & 21 & 24 & 27 & 30 & 33 & 36\end{array}$

$3 \quad \square \quad \square \quad 15 \quad 18 \quad 21 \quad 24 \quad 27 \quad 30 \quad 33 \quad 36$

$3 \square \square \square \square \quad 18 \quad 21 \quad 24 \quad 27 \quad 30 \quad 33 \quad 36$

$3 \square \square \square \square \square 2124 \quad 2730 \quad 33 \quad 36$

$3 \square \square \square \square \square \square 24273033 \quad 36$

$3 \square \square \square \square \square \square \square 273033 \quad 36$

$3 \square \square \square \square \square \square \square \square 3033 \quad 36$

$3 \square \square \square \square \square \square \square \square \square 3336$

$3 \square \square \square \square \square \square \square \square \square \square 36$

Step 12

$3 \square \square \square \square \square \square \square \square \square \square \square$ 